\title{
Nunca foram heróis! A disputa pela imposição de significados em torno do emprego da violência na ditadura brasileira, por meio de uma leitura do Projeto ORVIL \\ Priscila Carlos Brandão* Isabel Cristina Leite*
}

Resumo: Este texto aborda o processo de criação, execução e divulgação do Projeto ORVIL, a partir da perspectiva de um de seus principais executores: o então tenente-coronel "N2". O projeto foi pensado ainda no início de 1984 e

\footnotetext{
* Priscila Carlos Brandão é professora adjunta do Programa de Pós-Graduação em História da Universidade Federal de Minas Gerais, coordenadora do CEEIG (Centro de Estudos Estratégicos e Inteligência Governamental) da UFMG e líder do Diretório de Pesquisa do CNPq "Inteligência Governamental". Pós-doutora em Ciência Política pela Universidade de Burgos (2011) e doutora em Ciências Socais pela UNICAMP (2005). Desenvolve pesquisa sobre a reforma dos setores de informações/inteligência desde o período da ditadura brasileira e sobre a implementação do Sistema Brasileiro de Inteligência de Segurança Pública/SISP. Atuou como coordenadora do primeiro curso de Especialização em Inteligência de Segurança Pública promovido pela SENASP/MJ, em parceria com a UFMT. Também atua como consultora do Governo Federal e de alguns governos estaduais no processo de elaboração de políticas para a área de inteligência de Segurança. ** Isabel Cristina Leite é doutoranda em História Social na Universidade Federal do Rio de Janeiro (UFRJ) e tutora de História da América III na Universidade Federal do Estado do Rio de Janeiro (UNIRIO). Desenvolve a pesquisa: Ningún justificativo nos vuelve inocentes: a construção da memória sobre a luta armada na Argentina a partir dos anos 1970.
} 
Nunca foram heróis! A disputa pela imposição de significados...

propunha a elaboração de uma "Escrita da História" que deslocasse o discurso que vinha sendo produzido pelos militantes de esquerda acerca da tortura no Brasil, principalmente a partir da Anistia, e divulgado por meio de entrevistas e de uma extensa bibliografia memorialística. Permeado pelo discurso relativo à memória e às disputas realizadas em torno de sua imposição, o texto analisa, a partir da perspectiva individual, como esta construção se traduziu em um cenário institucional. Procuramos: a) compreender como um determinado grupo de militares, marcadamente ultraconservadores, concebiam-se no cenário do golpe militar e de implementação da repressão; b) perceber quais estratégias foram e ainda são utilizadas para contar e rememorar esse passado e, por fim; c) identificar quais fatores possuem capacidade de intervir nessa construção, tanto da perspectiva endógena, em termos de instituição, quanto exógena.

Palavras-chave: ORVIL. Serviços de Informações. Tortura. Memória. Ditadura Brasileira. Serviços Secretos.

\section{Introdução}

Obcecada pelas memórias de trauma e violência características dos regimes autoritários e totalitários do século XX, a sociedade contemporânea encontra-se imersa em uma espécie de obrigação permanente de recordar, de evocar o passado e torná-lo presente, passível de inquirição (HUYSSEN, 2004, p. 22). Necessidade que vem sendo interpretada e nominada de diversas formas pela historiografia, a exemplo da "hegemonia do efêmero", de Pierre Nora (NORA, 1994, p. 17-42), e da "sociedade musealizada", de Hugo Achugar (ACHUGAR, 2003, p. 199).

A construção da memória reflete a soma entre vários produtos individuais, resultantes de um processo particular entre o que se lembra, como se lembra e o que se esquece, por um lado, e um produto coletivamente compartilhado, resultante dos embates entre o que se deseja que seja lembrado e como, e o que se deseja que seja esquecido, por outro. Nesse ínterim, estão envolvidos todos os tipos de conflitos possíveis, sejam eles geracionais, corporativos, étnicos etc., porque, apesar de a memória ser uma reconstrução do passado, está orientada pelos interesses presentes. Assim, paradoxalmente, "a memória" é sempre um dos produtos da luta pela imposição de "determinadas memórias". Até mesmo da perspectiva individual, 
reflete experiências coletivamente compartilhadas em um contexto social, de existências que foram compartilhadas em harmonia ou de forma antagônica, em determinado espaço e tempo, e cujo "ato de lembrar" responde a interesses do presente.

A dinâmica do lembrar e esquecer ocorre sempre no momento presente. Não obstante, sua temporalidade é subjetiva, é relativa ao passado, ao mesmo tempo em que cobra vínculo com o presente e busca projeções para o futuro. Quando analisamos uma memória puramente dessa perspectiva, não existem formas de obstruir reinterpretações, leituras ou a elaboração de novos sentidos, pois, conforme destacam Elizabeth Jelin e Suzana Kaufman, "'...] al analizar la memoria, estamos frente a múltiples inter-subjetividades, múltiples transmisores y receptores de recuerdos parciales, múltiples sentidos, ambíguos, contracditórios, en puja."(JELIN; KAUFMAN, 1998, p. 11)

Assim, um trabalho sobre memória exige que se construa uma distância temporal necessária entre o pesquisador e o seu "objeto" de análise, um recuo que permita historicizá-la. Apenas dessa forma será possível analisar as transformações pelas quais passam cada um dos atores sociais envolvidos e compreender o que recordam ou esquecem, porque recordam ou esquecem (JELIN, 2002, p. 02).

"Como" e "porque" se lembra ou se esquece é uma discussão primordial neste trabalho. A tentativa de imposição de uma determinada memória e de esquecimentos específicos, oculta os embates existentes entre distintas memórias rivais. A construção dessa memória é um campo de luta política. Enquanto elemento cultural, a memória é capaz de construir significados e assim fortalecer o sentimento de pertencimento, mas, enquanto mecanismo político, a interpretação a ser fixada e reproduzida visa a legitimar determinados discursos, ao mesmo tempo em que busca desqualificar outros. $\mathrm{O}$ passado é interpretado em função destas lutas do presente.

Tais embates são particularmente conflitantes, quando estão em disputa memórias dos militantes de esquerda e aquelas defendidas pelos organismos de Defesa dos Direitos Humanos, por um lado, e a memória de militares, do outro, no contexto das recentes ditaduras latino-americanas. Mais do que imprimir significados, as lutas pela demarcação dessa memória possuem um caráter 
Nunca foram heróis! A disputa pela imposição de significados...

instrumental, uma vez que envolvem a possibilidade de compensação (e definição) de vítimas, a atribuição de responsabilidades àqueles que recorreram ao uso da violência, bem como o reconhecimento público e institucional sobre o desencadeamento de determinados crimes. Tratam-se de batalhas dominadas por paixões e convicções, como destacam Felipe Aguero e Eric Hersberg, com uma dose nada desdenhável de cálculos estratégicos, cujas estratégias, não raro, resultam inoportunas, mal concebidas ou deslocadas da realidade. (AGUERO; HERSHBERG, 2005, p. 02)

Há pelo menos quarenta anos, existe uma tentativa de se fixar um relato padrão entre os militares do Cone Sul para explicar os processos que levaram às ditaduras, assim como justificar as violações aos direitos humanos durante estes regimes. Este relato está centrado no combate à subversão e na precariedade dos governos que antecederam aos golpes militares (MARCHESI, 2005, p. 175). Dessa maneira, há uma tentativa de construir uma memória baseada no heroísmo castrense e na defesa dos valores nacionais, frente ao inimigo "subversivo marxista", que muito povoou o imaginário popular sobre sua suposta periculosidade (MOTA, 2002, p. 37).

Com o presente artigo, visamos a reconstituir e apresentar alguns debates desta tentativa de imposição de memória construída pelos militares no apagar das luzes da ditadura militar no Brasil, assim como problematizar sua inserção em um contexto maior de busca de legitimidade sobre a narrativa do passado. Para tanto, centraremos nossa pesquisa no denominado Projeto ORVIL (anagrama de "livro", em português) que veio à tona em 2007, por meio da análise do documento que lhe deu origem, do depoimento de um de seus principais executores e de alguns discursos deste projeto, ainda hoje em dia atuantes, por meio do site TERNUMA ${ }^{1}$.

Optamos por privilegiar o depoimento como fio construtor de nossa pesquisa, pois entendemos que há a construção de uma narrativa plausível sobre os fatos que levaram ao aparecimento do ORVIL. Todavia, estamos conscientes do processo de construção de memória ali envolvido. Entendemos que a divulgação de parte desta documentação do ORVIL, na internet, funcionou como um "nó convocante" da memória, que conduziu o depoente à releitura do próprio regime militar e suas ações e reafirmação de suas posturas 
dentro da hierarquia militar e de suposto compromisso com a sociedade, no sentido de se contar o que "realmente aconteceu". $\mathrm{Na}$ disputa pela legitimidade da reconstrução do período da ditadura militar, os militares construíram uma racionalidade acerca do tema, enfatizando aspectos da vida militar e subestimando valores da vida civil (D’ARAÚJO; CASTRO, 1994, p. 04)

Estamos cientes de que está sendo apresentada uma versão da história, que, como veremos, poderá ser confrontada com outra divulgada pelo jornalista Lucas Figueiredo, nas questões que se referem, principalmente, à origem e às motivações do livro, trazidas a público por meio de uma série de reportagens sobre o ORVIL, produzidas em 2007, e que mais tarde deram origem ao livro: Olho por olho. Os livros secretos da ditadura, publicado em 2009.

Manipular e cotejar estas duas fontes é uma tarefa delicada, em função do teor dos dados contidos no livro, que se baseia, como será visto adiante, em Informes produzidos pelas Forças Armadas e por depoimentos de militantes. Atualmente, já se sabe que no Brasil, como também no Paraguai, parte desses documentos "confessionais" de militantes foram produzidos em situações-limite, como a tortura (JELIN; CATELA, 2002, p. 05). De todo modo, o aparecimento do ORVIL reanimou o debate acerca da busca pela legitimidade da memória da ditadura civil-militar brasileira e evidenciou que ainda há muito o que se descobrir e discutir sobre o tema.

\section{O Projeto}

Pensado ainda no começo do ano de 1984 como uma forma de se contrapor ao destaque que ganhavam as memórias de militantes de esquerda sobre a ditadura militar brasileira, o projeto ORVIL não pode ser compreendido separadamente do seu processo de extensiva divulgação, iniciado em 2007, e que tem continuidade por meio dos sites do projeto TERNUMA e do Jornal Inconfidência ${ }^{2}$, bem como sem uma análise sobre seu principal mentor e executor: N2 ou F. Dumont, conforme pseudônimos adotados pelo autor em entrevistas (N2) e nos sites do projeto TERNUMA e do Grupo Inconfidência (F. Dumont) ${ }^{3}$. 
Nunca foram heróis! A disputa pela imposição de significados...

Considerar parte da trajetória deste ex-analista de informações do Centro de Informações do Exército é fundamental para a compreensão da batalha que vem sendo empreendida por alguns militares, no sentido de impor sua versão dos fatos sobre a aplicação da violência durante a recente ditadura. Neste sentido, pode ser dividida em três tempos: 1984 - quando N2 elabora a Apreciação que destaca a necessidade de se reescrever a história das esquerdas no Brasill'; 2007 - quando a divulgação da obra pela mídia o incentiva a falar mais detalhadamente do projeto; e a partir do final de 2010 - quando, após sua aposentadoria definitiva, sob o pseudônimo de F. Dumont, começa a publicar sistematicamente, no site do TERNUMA, análises detalhadas sobre organizações de esquerda, retiradas do próprio projeto, cujo teor já se encontra disponível para download em sua íntegra.

Optamos por privilegiar o depoimento como fio construtor de nosso trabalho, pois entendemos que existe a construção de uma narrativa plausível sobre o desencadeamento do projeto, endossada por documentação, e por uma política identificável de N2, de manter o debate aceso, por meio de suas publicações no site do TERNUMA. Estamos conscientes do processo de construção de memória envolvido, que estamos apresentando uma versão da história, que será confrontada com outra, divulgada pelo jornalista Lucas Figueiredo, trazidas a público em uma série de reportagens sobre o ORVIL em 2007, que posteriormente ensejaram a publicação do livro: Olho por olho. Os livros secretos da ditadura, em 2009.

Manipular e cotejar estas duas fontes é uma tarefa delicada, face o teor dos dados contidos no livro, baseados principalmente em Informes $^{5}$ e em depoimentos de militantes. De todo modo, o aparecimento do ORVIL reanimou o debate acerca da busca pela legitimidade da memória da ditadura e evidenciou que ainda há muito o que descobrir e discutir sobre o tema.

\section{A história narrada por $\mathbf{N} 2$}

Pensado ainda durante o governo do último general-presidente, João Batista Figueiredo, em 1984, por um analista do Centro de 
Informações do Exército (CIE), o projeto que posteriormente seria nominado ORVIL visava à construção de uma narrativa histórica baseada na visão dos "vencedores". Preocupado com a memória produzida pelos "terroristas" por meio de um "Trabalho de Massa" (mídia, movimentos estudantil, religioso, político, sindical), ${ }^{6}$ e concretizado pela publicação de livros autobiográficos ${ }^{7}$ e divulgação de entrevistas, N2 expressou ao chefe do CIE a necessidade de viabilizar a construção de uma "história verdadeira", que deslegitimasse o discurso realizado pelos comunistas. Estes estariam atuando agressivamente, deturpando os fatos, distorcendo as notícias, imprimindo significados diferentes aos "fatos históricos". Faziam com que a "história da subversão", que "já havia ficado na história", fosse reescrita "do modo que lhe é conveniente". 8

A história da subversão já havia sido colocada pelos militares em seu devido lugar, principalmente por meio da anistia. O debate em torno da publicação desta versão "deturpada", que transformava "antigos terroristas" em heróis, implicava revolver o passado, cujo esquecimento era uma das condições básicas do compromisso não escrito da transição: "Os terroristas de ontem, estão sendo, hoje, glorificados, ganhando nomes de ruas, praças e avenidas. Nas assembleias legislativas os Lamarcas são descritos como patriotas e defensores do povo"'.

Mas uma vez remexida essa história, era necessário reescrevê-la de forma a transformar as "vítimas" dos terroristas em heróis. Era preciso homenageá-los, reverenciar suas famílias:

Enquanto isso, os que deram o sangue contra a subversão foram esquecidos. Seus filhos nunca viram um ato de reconhecimento pelo sacrifício de seus pais. E pior: constantemente vêem seus nomes tachados de sádicos torturadores, opressores e reacionários ${ }^{10}$.

Evidentemente preocupado com o público interno e com o papel que estaria sendo pensado para as Forças Armadas em um processo de transição, propunha construir uma história que não permitisse aos jovens militares repetirem as histórias que estariam lendo e escutando, de que os militares nada mais teriam sido do que 
Nunca foram heróis! A disputa pela imposição de significados...

"radicais de direita, corruptos" e "agentes do imperialismo ianque". Por outro lado, era preciso reafirmar a imagem dos "terroristas" como "delinquentes e clandestinos"11.

Para tanto, foi proposto um plano de pesquisa que seria realizado em três fases sucessivas: a) Primeira fase (curto prazo): seleção dos casos mais conhecidos de ação dos guerrilheiros, para posterior produção de slides, ilustrações e quadros a serem divulgados em aulas ou palestras; b) Segunda fase (médio prazo): ampliação da pesquisa para casos menos conhecidos e; c) Terceira fase (longo prazo): produção de livros amparados por essas informações ${ }^{12}$. De acordo com N2, apesar de haver "muita coisa que não pode ser contada", os militares tinham os dados e os fatos para a construção desta, apenas faltava-lhes "a vontade e a decisão". ${ }^{13}$

\section{Figura 1 - Nosso personagem e sua luta}

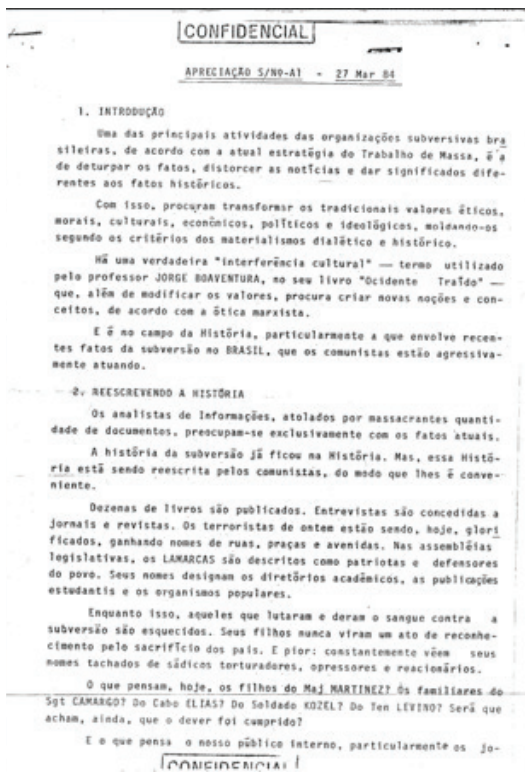

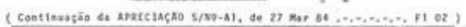

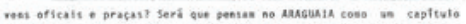

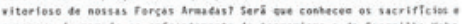
- sangui derramedo no enfrentasento do terrariaso. do Guerrithe urba

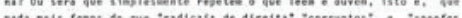

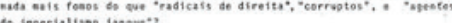

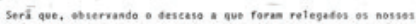
conbotentes, se for aecessífio olsu dio pegario en orass ceatrs un nossivel future twts Arnade?

3. O sat razca

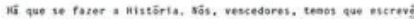

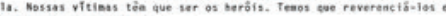
bonesigear swas fanticas.

Os tarreristas têa que ser anstruces coso delingabentes. A cone Elondestings.

Os exemplos, positives onegatives, tến que ser datos it sovas

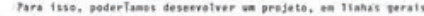
con as segutetes tasest

-10 fase - . curto grazo:

seleciacar as casos mis centecioes.

realizar entrevistas o pesevisos.

- escrever os casos, sistortando-os en quadriahos.

tivstrą̧ōes e s11đeș

- Etrolgä-los, atrovbs de sulas e evtros seles.

- za tase - D eisto pracos

ampliar pars as casos menes conhecites.

- 3. fase - a longe pratas:

encrever livros, nats tompletos.

Steultaneasente. poderia ser sesenvolvido un prograns th heaen geas abs asssos mertos, coes a prestego dos fastliteres.

4. cenciusas

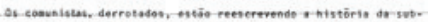
versib. os attigas terreristas ettio se tornando is herbis de haje.

Cequanto isso, of allitures martos op cunpriaento of dever es.

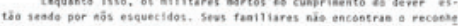
enquectides. Sevt tanilition

Apreciação S/No A1 - 27 Mar 84

Anos 90, Porto Alegre, v. 19, n. 35, p. 299-327, jul. 2012 
Mas quem é este personagem que, no limite de sua obediência, não apenas provoca o debate, mas também questiona o comportamento de seus superiores, ao sugerir que faltaria vontade política do Exército, ainda em pleno regime militar, para escrever sua própria história?

Pois bem, N2 era um tenente-coronel do Exército e havia se tornado membro do extinto CIE apenas um ano antes, em 1983. Ingressou na carreira militar em 1962, por influência de um tio e, em 1969, teve seu primeiro contato com a área de informações, por meio do Curso de Informações do Centro de Estudo Pessoal do Exército (CEPE). Em função de seu ótimo desempenho como aluno, teria sido convidado a lecionar no Centro no ano seguinte, prosseguindo com suas aulas, mesmo quando o curso foi transferido para a Escola Nacional de Informações (ESNI), criada em 1971 ${ }^{14}$. Atuou no Destacamento de Operação Interna (DOI) entre 1975 e 1981 e teria sido, segundo seu depoimento, o responsável por desenvolver uma capacidade de coleta e análise de informações e por suprimir "a parte operacional do DOI"15. Ou seja, está afirmando que teria acabado com o processo de tortura e prisões a partir de meados da década de 1970.

Formado em Filosofia e profundo conhecedor dos discursos hegeliano e marxista, N2 define-se como um homem da área de análise de informações, o qual, em função de sua experiência e conhecimento (teria sido considerado o maior especialista em esquerdas do país naquele período), foi convidado, em 1983, a integrar o CIE. No papel de analista e "observador", atento às publicações do período, teria se alarmado face o número de livros que vinham sendo editados no - e sobre - o país, que abordavam a questão da violência empreendida pelo governo após a "revolução democrática”. Em sua concepção, esta leva de informações faria parte de uma trama da esquerda para desqualificar e deslegitimar a atuação dos militares. Tal literatura, em sua maior parte composta de depoimentos e biografias, seria responsável por fixar uma memória "falsa" sobre a atuação do Exército, que sempre teria agido em defesa dos interesses democráticos e da ordem.

Lendo a emergência e o crescimento dos discursos proferidos pelos militantes como uma nova "[...] tentativa de tomada do poder", 
Nunca foram heróis! A disputa pela imposição de significados...

N2 sugeriu a seu chefe imediato, por meio da Apreciação S/ ${ }^{\circ}-\mathrm{A} 1$, de 27 de março de 1984, que se escrevesse uma outra história. Tal sugestão seria acatada apenas em 1985, já no governo José Sarney, durante a gestão do Ministro do Exército, Leônidas Pires Gonçalves:

Isso aqui deve ter ficado como um gérmen na cabeça de algumas pessoas. Quando chegou em 1985, quando o coronel Agnelo Del Nero assumiu a Seção de Análise do CIE, eu mostrei isso aqui [a Apreciação] para ele. Não sei se ele já tinha vindo com essa ideia ou não, ele assumiu isso aqui, para fazer um livro. ${ }^{16}$

A pesquisa foi dividida de forma mais ou menos equilibrada entre os membros. O chefe do CIE reuniu alguns de seus oficiais em busca de ideias, entre as quais N2 destacou a fornecida por membros da Seção de Contrainformações, que propunham a contratação de escritores para a redação da pesquisa que seria realizada pela área de informações. Por falta de recursos, a proposta foi recusada e o chefe do CIE articulou o desencadeamento da pesquisa a partir do material humano disponível, seus analistas.

Inicialmente, ainda em meados de 1985, Del Nero teria adotado a metodologia de dividir as principais organizações comunistas entre os analistas e estabelecido um prazo de dois meses para que cada um pesquisasse e produzisse um documento sobre determinada organização de esquerda ${ }^{17}$. N2 relatou que produziu um documento muito rápido sobre o Movimento Revolucionário Tiradentes e o encaminhou para o coronel, que teria ficado impressionado com a qualidade do trabalho e com o nível de sua capacidade analítica. Em função deste destaque (em sua concepção, o fato de ter cursado Filosofia contribuí para a sofisticação de suas análises), Del Nero optou por lhe repassar os documentos que estavam sendo produzidos por outros analistas, de modo a empreender um processo de revisão, verificando se as informações acerca das organizações estariam corretas. As fontes consultadas foram os informes, informações coletadas em relatórios periódicos, documentos de operações e, principalmente, depoimentos coletados durante interrogatórios ${ }^{18}$. 
Entretanto, os problemas na pesquisa logo surgiriam, acarretando uma interrupção do trabalho: "Isso aqui não dá para continuar, é que tinha morto assaltando banco. $\mathrm{O}$ terrorista tinha sido morto em abril, e estava assaltando banco em julho"19. De acordo com o depoente, os erros ocorriam em virtude da composição heterogênea destes analistas, especialistas em movimentos outros, que não as organizações comunistas ${ }^{20}$.

Seriam necessários outros critérios e a solução de Del Nero teria sido a de designar N2 - especialista em organizações de esquerda - o responsável por toda a pesquisa sobre organizações comunistas. O trabalho foi repensado em termos cronológicos. Assim, em janeiro de 1986, iniciava-se o trabalho que levaria o nome de As quatro tentativas de tomada de poder.

A primeira tentativa [de tomada do poder] era a de 35 , a segunda tentativa era a de 63/64, a terceira tentativa era essa da luta armada [67/74], e a quarta tentativa que era essa, trabalho de massa, que tava começando naquela época 84/85. Então, essa quarta tentativa abriu as ideias para que nós íamos enfrentar um novo surto de tentativa de tomada do poder. $\mathrm{E}$ deram. Não exatamente comunista, mas à esquerda ${ }^{21}$.

Para o desenvolvimento de tamanho trabalho, o analista teria contado apenas com a ajuda de um sargento, responsável por datilografar o que escrevia a próprio punho, além das considerações elaboradas pelo coronel Del Nero (N1). Em função da diferença das redações, teriam optado por realizar uma padronização das análises, que teria ficado sob a responsabilidade de N2. Outra divisão de funções havia sido estabelecida entre os dois, Del Nero teria ficado com a incumbência de pesquisar e produzir análises de conjuntura, sobre a política e as ações militares dos anos de 1960 e 1970, enquanto N2 desenvolvia o seu estudo sobre as organizações ${ }^{22}$. Segundo N2, ele teria realizado cerca de 60\% do conjunto da pesquisa e passado a tarefa adiante, a partir do debate sobre a Guerrilha do Araguaia, quando N3 assumiria.

O resultado da pesquisa está descrito em dois volumes de caráter reservado, perfazendo um total de mais de 900 páginas. O 
Nunca foram heróis! A disputa pela imposição de significados...

primeiro volume começa com Uma explicação necessária, na qual o coordenador da pesquisa manifesta sua preocupação em contar para a juventude a história do país e narrar o processo de luta armada, principalmente entre os anos de 1969 e 1973. Contudo, à medida que foi sendo desenvolvida uma série de questionamentos sobre a raison d'être destes agrupamentos guerrilheiros se tornaram evidentes: Quais suas matrizes ideológicas? Como se formaram, estruturavam, quais seus objetivos, quais modelos e métodos estrangeiros queriam transplantar para o país, em quais seguimentos sociais buscavam militantes? ? $^{23}$

Tendo em vista que o objetivo do ORVIL seria a construção de uma memória sobre a guerrilha que desmobilizasse a versão que estava sendo construída pela esquerda, as questões levantadas não poderiam se limitar às supracitadas, que se referiam unicamente à dinâmica guerrilheira e suas raízes. Necessitava-se evidenciar os dilemas enfrentados pela direita para combater o "terrorismo" que desestruturava o status quo: em que nível as ações guerrilheiras colocavam em cheque o monopólio da força armada organizada? O seu combate exigia o envolvimento das Forças Armadas? Estariam preparadas e estruturadas para este combate insólito (grifo nosso)? Quais sacrifícios lhes foram impostos? Venceram a luta? ${ }^{24}$

Tais questões foram apenas o início de uma pesquisa minuciosa que retrocede no tempo, até chegar às origens das ações do Partido Comunista Brasileiro; nas diferentes vertentes teóricas do comunismo; nos congressos e nas dezenas de cisões, tudo sendo contextualizado e reconstituído histórica e factualmente, fornecendo uma ampla perspectiva da atuação da esquerda ao longo de nossa história republicana. Construiu-se uma narrativa bem estruturada, ainda que cheia de rótulos e juízos de valor fortemente conservadores, que buscava referências nos clássicos marxistas, repleta de mapas, cenas de crime, fotografias de militantes e de suas vítimas, de modo a tentar comprovar que, por três vezes, o país esteve próximo a uma tomada de poder pelos comunistas. Na quarta tentativa, a esquerda, não necessariamente os terroristas, finalmente "o tomariam", como evidencia o discurso de N2, ao afirmar que o MR8 estava no poder durante o governo Sarney, que Fernando Henrique havia se tornado presidente etc. ${ }^{25}$ 
A primeira tentativa de tomada de poder remonta a 1935, com o levante comunista, pejorativamente tratado por Intentona. Segundo os autores do ORVIL, como muito já havia sido escrito sobre o episódio de 1935, restava-lhes "relembrar os atos de terror" daqueles dias e levantar hipóteses acerca de seu fracasso. Para além da não adesão de outros setores sociais à causa, os pesquisadores militares tentavam responder outros questionamentos, para tentar entender o fracasso da tentativa de tomada do poder conduzida pelo Partido Comunista. Sob a direção de Luís Carlos Prestes: "Houve estreita interpretação do materialismo histórico? A crença de que bastava um partido resoluto para impulsionar o processo revolucionário? Erro de avaliação da realidade nacional? Superestimação do papel dos militares comunistas? Cumprimento incondicional às ordens da Internacional Comunista"?26 O levante comunista foi, desse modo, classificado como "[...] um crime que ceifou dezenas de vidas e que se poderia repetir no momento em que seus idealizadores julgassem haver um amadurecido processo revolucionário"27.

N2, em seu processo de narrativa exposto no site do TERNUMA em 11/01/2011 (agora sob pseudônimo F. Dumont), busca reforçar a imagem de um Prestes frio, calculista, sanguinário e hipócrita, ao destacar o assassinato de Elza Fernandes (adolescente amante de Miranda, então Secretário Geral do Partido, "justiçada" pelos "terroristas", em 1936) e sua recusa, nos anos que se seguiram, em falar sobre o assunto. Desconfiados de que Elza os teria traído, o "Tribunal Vermelho" decidiu por seu assassinato, mas teria vacilado em sua execução, a qual ocorreu mediante uma ordem de Prestes, em conhecida carta por ele enviada aos seus companheiros:

[...] fui dolorosamente surpreendido pela [...] vacilação de vocês. [...] ou [...] concordam com as medidas extremas e neste caso, já deviam ter colocado a resolução em prática, ou então discordam, mas não defendem como devem, tal opinião. ${ }^{28}$

Após narrar com minúcias a execução de Elza, destacando a violência empreendida, N2 não perde a chance de ironizar a situação, ao destacar que "A reação do 'Cavaleiro da Esperança' 
Nunca foram heróis! A disputa pela imposição de significados...

foi imediata", assim como destaca que Prestes, em poucos meses, passaria por situação semelhante, quando sua esposa Olga Benário foi entregue a Hitler ${ }^{29}$.

A segunda tentativa de tomada de poder abarca os anos que antecederam ao golpe de 1964. Teria ocorrido já dentro do cenário das cisões com o PCB, que deram origem à chamada nova esquerda no Brasil, organizações e partidos clandestinos críticos ao PCB, surgidos no início da década de 1960 (REIS; SÁ, 1997, p. 07). São matrizes dessa nova esquerda duas organizações, quais sejam, Política Operária (POLOP) e Ação Popular (AP), e um partido, o Partido Comunista do Brasil (PC do B $)^{30}$. De acordo com a análise contida no ORVIL, a ascensão de João Goulart ao poder, trazendo consigo figuras radicais da esquerda, como Leonel Brizola - que propunha abertamente a luta armada - e Miguel Arraes, ao mesmo tempo em que a Nova Esquerda ganhava simpatizantes, os sindicatos fortaleciam-se, e parcela das Forças Armadas se insurgiam contra a situação nos quartéis, é que teria forçado a necessidade de intervenção militar como forma de pacificar o país e evitar a ditadura do proletariado, que seria implantada pelo governo comunista de Jango.

Sobre estas perspectivas, não podemos deixar de destacar novamente a ironia de N2, expressa tanto em suas entrevistas quanto em sua redação, que, ao narrar a emergência do Grupo dos Onze, organização criada por Brizola e Neiva Moreira ainda em 1963, realiza uma analogia com o filme dirigido por Mário Monicelli (1965), ao intitular sua análise como O incrivel Exército de Brizoleone, exposto em seis capítulos na página do TERNUMA, em 04/02/2011.

A terceira tentativa de tomada de poder seria a mais óbvia e a que mais teria motivado a proposta da pesquisa. Esta tomada ocorreria via luta armada, através das várias organizações guerrilheiras existentes e atuantes, principalmente entre os anos de 1967 e 1973. Há um exaustivo trabalho de análise dos programas de todas as organizações de esquerda, seus militantes - incluindo a atuação de alguns deles no exterior -, bem como as ações de assaltos, sequestro de embaixadores e confronto com a polícia. Não é de se estranhar a descrição minuciosa das medidas políticas "legitimadoras" do governo militar, que também visavam a justificar o fechamento do regime em 1968, por meio do Ato Institucional No5. Quando o 
assunto é a tortura, por exemplo, é evidente a negação do fato. É tida como uma tentativa dos guerrilheiros de manchar a imagem do governo no exterior, com apoio da Amnesty International, dando ênfase ao que os militares chamavam de "psicopolítica":

Em meados de 1970, a Amnesty International publicou e difundiu o documento "Mission d' Enquete au Brasil". O texto, segundo a publicação, representava o resultado de uma pesquisa que teria sido realizada por dois advogados da Corte de Apelação de Paris, Louis E. Pettiti e Jean Louis Weil, sobre a situação dos presos políticos no Brasil. Após acusar a legislação revolucionária de discriminatória, o relatório admitia a existência de tortura contra os presos políticos no Brasil. Descrevia, pormenorizadamente, todos os tipos de tortura possíveis e imagináveis, e alegava que seriam elas impostas aos prisioneiros no Brasil. A partir dessa publicação, qualquer subversivo que tivesse a oportunidade de ser entrevistado podia "escolher o tipo de suplício" - que desejava fazer crer - a que tivesse sido submetido. Ninguém se perguntou quem eram Louis E. Pettiti e Jean Louis Weil, quais suas ideologias, quais seus objetivos... O homem é assim, daí o êxito da psicopolítica ${ }^{31}$.

Citando Esquerdismo, doença infantil do comunismo, de Lênin, a fracassada terceira tentativa é narrada não apenas como "uma estupidez, como também um crime"32 sobre a qual julgaram irresponsável a doutrinação cubana realizada entre os jovens estudantes; inútil a atuação do "clero progressista", que manipulou pessoas de boa fé; e o que mais indignou, a forma com a qual "líderes egocêntricos" agrediram psicologicamente tais jovens, baseando-se na difamação das Forças Armadas e deturpação da realidade brasileira ${ }^{33}$.

Pela lógica castrense, após o fim da luta armada, os militantes da esquerda revolucionária buscaram transformar sua derrota militar em vitória política, pois teria sido constatado, após o período de autocrítica destes grupos, que foi o afastamento das massas um dos responsáveis pelo fracasso do empreendimento armado. Assim, o 
Nunca foram heróis! A disputa pela imposição de significados...

novo foco dos militantes de esquerda tornar-se-ia, justamente, o acesso a essas massas, em sua quarta tentativa de tomada do poder.

\begin{abstract}
O trabalho de massa consiste na propagação da ideologia e na utilização das técnicas de agitação, de propaganda, de recrutamento e de infiltração, valendo-se de todos os meios de comunicação social para atuar sobre os diferentes segmentos sociais (movimento operário/sindical; movimento educacional; movimentos populares; etc), a fim de conscientizar a massa para a necessidade de fazer a revolução. Objetiva, particularmente, conquistar a população, sobretudo fazendo com que perca a fé nos governantes, no regime e nas instituições, dominar, especialmente por meio da infiltração, as estruturas governamentais; e educar, organizar e orientar os diversos segmentos sociais para a revolução ${ }^{34}$.
\end{abstract}

A partir do processo de distensão política em 1974, os antigos militantes passaram a abraçar causas diversas, a exemplo da anistia, da revogação do AI-5, da livre organização dos direitos políticos, do respeito aos direitos humanos, da extinção dos órgãos de repressão e punição dos envolvidos em crimes durante a ditadura. Esta nova estratégia efetivaria, na concepção dos autores, a possibilidade de prepararem-se para uma nova tentativa de tomada de poder " [...] com segurança, com a garantia do direito, valendo-se da prerrogativa que só este regime paradoxal - a democracia, sem aspas e adjetivos - oferece: a possibilidade de seus inimigos prepararem-se para a tomada do poder sob o amparo da lei" 35 .

Os processos eleitorais para governadores, em 1982, e para presidente, em 1984, significariam a efetivação do projeto político junto às massas, desencadeado pelos antigos subversivos. Segundo os militares, não bastou aos guerrilheiros tão-somente o fim dos governos ditatoriais e a chegada dos civis ao poder. A "ardilosa" esquerda passaria agora fazer a população "desacreditar da Revolução de 64”, negar seus êxitos, e proclamar a "farsa do milagre econômico". Em tom de desabafo, escrevem: 
Imanente a todo este trabalho estava o objetivo de atingir os seus algozes - agora as próprias Forças Armadas - que não só recentemente, como em 1935 e 1964, haviam sido o obstáculo mais sério a suas tentativas de tomada de poder, com o fito de afastá-las ou neutralizá-las como empecilhos à sua caminhada ${ }^{36}$.

Mas para além da construção da "verdade" militar sobre a luta armada e o período ditatorial, o ORVIL apresentou informações até então desconhecidas. Mais de 1,7 mil pessoas - entre guerrilheiros e artistas famosos - foram citados, além de trazer informações inéditas sobre o destino de ao menos 23 desaparecidos políticos, sobre os quais repetiam, ao longo de mais de 30 anos, que não se tinha notícias. Reside aí, talvez, uma das mais importantes contribuições do documento.

O projeto, apesar de desenvolvido ao longo de três anos, não foi imediatamente divulgado. De acordo com N2, a decisão de Leônidas Pires de não publicar o livro estaria relacionada ao momento político do país e aos impactos políticos negativos que poderiam acarretar à instituição militar, no momento em que as bases da transição ainda não estariam fortemente assentadas. ${ }^{37}$ Seus resultados foram mantidos em stand by, como uma arma guardada, a ser usada apenas em caso de necessidade. Conforme argumenta o próprio general Leônidas, guardada como uma arma, contra um possível revanchismo em relação às Forças Armadas, por parte de "quem perdeu a guerra".

Naquele tempo (em que o livro foi feito) não havia o que acontece agora, um revanchismo sem propósito. [...] No meu período como ministro (1985-1990), não houve nenhum problema dessa natureza, essas 'mães não-sei-do-quê', Tortura Nunca Mais. ${ }^{38}$ 
Nunca foram heróis! A disputa pela imposição de significados...

\section{Uma luta pela memória}

Temos claro que a narrativa ora apresentada versa sobre uma leitura muito específica sobre o processo de construção do ORVIL, que vem sendo tratado de várias formas pela mídia, por militantes ou por acadêmicos que têm aprofundado suas pesquisas sobre o tema. O projeto já havia sido abordado pelo coronel Brilhante Ustra em sua obra $A$ verdade sufocada, publicada no início de 2006; já havia sido comentado em entrevista realizada em agosto daquele mesmo ano; quarenta páginas de seu texto já estavam expostas no site do TERNUMA; e alguns trechos já haviam sido utilizados por militares que publicaram sua versão dos fatos e/ou suas memórias, sem identificar suas fontes ${ }^{39}$. Mas foi a partir da divulgação do projeto e seu conteúdo pelo jornalista Lucas Figueiredo, em uma série de reportagens especiais que saíram simultaneamente nos jornais Estado de Minas e Correio Braziliense ${ }^{40}$, posteriormente transformadas em seu livro Olho por olho ${ }^{41}$, que o tema tomou maiores proporções. Até esta divulgação, não se sabia a origem das informações contidas nesse site ou nos livros, cujo teor expressa o ponto de vista de militares ultraconservadores. Tampouco era sabido que essas páginas integravam uma empreitada muito maior.

Não obstante, um pouco diferente do que conta Lucas Figueiredo, a iniciativa do ORVIL não foi uma resposta ao projeto Brasil: Nunca Mais (BNM), produzido em oposição ao relato construído pelos militares durante a ditadura (o projeto BNM, assumido pela Arquidiocese de São Paulo, resultou na publicação do livro Um relato para a história: Brasil Nunca Mais, lançado em 1985, que rapidamente alcançou a posição de um dos livros mais vendidos do país). Como visto na entrevista e corroborado pela Apreciação datada de 23 de março de 1984, a disputa pela fixação de uma memória sobre a atuação da esquerda no país e o sistema repressivo já havia começado muito antes de se ter conhecimentos sobre o projeto da Arquidiocese. A autorização para a sua execução é que foi concedida apenas depois de adquirido conhecimento sobre o mesmo, o que nos leva a discordar da afirmativa que a ideia do livro teria partido do ex-ministro Leônidas Pires. 
Muito comenta-se que a repercussão causada pelo aparecimento do ORVIL evidenciou a temática acerca da abertura dos arquivos da ditadura e da reabertura de alguns processos para a indenização de famílias. O então ministro-chefe da Secretaria Especial de Direitos Humanos, Paulo Vanucchi, manifestou-se à época, dizendo que haveria uma "pressão diferente" para a abertura dos arquivos sigilosos, e que chamaria o General Leônidas Pires para depor. Mas, como não se tocou mais no assunto, foram os familiares dos desaparecidos que reivindicaram a abertura dos arquivos que embasaram o livro, para que se pudesse ajudar a localizar os corpos ${ }^{42}$.

Interessante destacar que alguns militares, através de publicações de extrema direita, também bradavam pela abertura dos arquivos e faziam provocações aos antigos militantes. $\mathrm{O}$ exemplo mais evidente é o jornal do Grupo Inconfidência, que, na semana da publicação das reportagens, lançou o editorial Abrindo os arquivos da "ditadura". No texto, argumenta-se que se o objetivo da abertura dos arquivos fosse alentar os familiares dos mortos e desaparecidos e o "resgate da verdade" sobre o período, a esquerda sairia frustrada, pois iriam encontrar apenas descrições sobre "crimes que cada um dos 'heróis' terroristas praticou [...] incluindo detalhes cruéis e nomes das vítimas". ${ }^{43}$ Destoando deste discurso, o general Pires Gonçalvez acreditava que não se deveria abrir arquivos e divulgar aquilo que é passado: "Vamos olhar para frente", afirmou (LEITE, 2009, p. 231).

De todo modo, o projeto ORVIL foi desenvolvido dentro de um governo dito democrático. Várias questões acerca do livro precisam ser respondidas, como afirma Suzana Lisboa, destacada militante dos Direitos Humanos: Onde estão os documentos que foram base para o livro? Quem colaborou? Quanto custou? ${ }^{44}$

E é por aqui que entram as análises sobre o ORVIL, específicas de nosso trabalho, vista a partir da perspectiva de um de seus executores. Em primeiro lugar, cremos importante inverter a ordem dos fatores. Mais do que compreender a divulgação do projeto como um ganho dos familiares de mortos e desaparecidos, é preciso entender a divulgação do ORVIL como uma estratégia astuta de militares de ultradireita, de questionamento à política de indenizações que vem sendo desenvolvida pela Secretaria Nacional de Direitos Humanos, e 
Nunca foram heróis! A disputa pela imposição de significados...

que transforma Lamarcas, em heróis. Em sua perspectiva, é a "bolsa ditadura" ou "bolsa guerrilha" quem está sendo questionada.

Mas também podemos observar que - claro que não há unanimidade -, ao invés de admitirem e aceitarem as consequências de serem atores responsáveis pela interrupção da ordem democrática, constitucionalmente estabelecida, estes "autores" - expoentes de uma linha ultraconservadora - não admitem uma autocrítica, conforme as próprias esquerdas vêm realizando desde a década de 1990.

Em sua obra Ditadura militar, esquerdas e sociedade, Daniel Aarão Reis, ex-militante do MR8, discorre sobre os deslocamentos de sentido produzido no país, que procuraram se fixar na memória nacional enquanto verdades absolutas, correspondentes ao processo histórico objetivo, e não a versões consideradas apropriadas por seus autores. Principalmente os partidários da anistia e os militantes em defesa dos Direitos Humanos, apresentaram os guerrilheiros como o braço armado da resistência democrática ao regime, apagando a perspectiva ofensiva e revolucionária que os havia moldado. No entanto, "[...] não eram de modo algum apaixonadas pela democracia, francamente desprezada em seus textos" ${ }^{45}$. Uma memória que, de maneira alguma, poderia ser apresentada de forma unívoca, dado que a memória das esquerdas reflete seus múltiplos movimentos, rachas, dissidências, tornando impossível atribuir-lhes algum nível de organicidade.

Ao contrário do que veio lentamente fazendo essa esquerda, os militares insistem em afirmar que sua conduta foi uma resposta legítima à violência daqueles que teriam se recusado ao diálogo e optado pelo radicalismo e ilegalidade, ao tomarem iniciativas de pegar em armas e "desencadear ações criminosas", conforme consta em resposta elaborada pelo Centro de Informações do Exército, após a divulgação das evidências de que o jornalista Vladimir Herzog teria sido assassinado em suas dependências, em outubro de $2004^{46}$. Como se houvesse opção para o diálogo em alguma esfera política naquele momento, como se o debate no Congresso não fosse cerceado pelas diversas cassações que haviam lhe sido impostas.

$\mathrm{O}$ discurso militar é um pouco dividido no que tange às formas de se proteger a instituição. Como visto, os ultraconservadores bradam a abertura dos arquivos como meio de evidenciar a 
postura violenta da esquerda e legitimar a forma e o grau com que a repressão foi implementada (daí a divulgação do ORVIL), ao passo que outros militares primam pelo esquecimento deste passado, que deve ser tratado enquanto uma história que já passou. Os dois a defendem, ainda que de maneira distinta. Mas a memória sobre o desencadeamento do golpe em si, evidente no discurso de N2, pode ser considerada um discurso relativamente homogêneo. No papel de defensores da nação e da civilização cristã ocidental, argumentam que a intervenção era uma condição necessária para a proteção do país, cuja unidade estaria ameaçada tanto externa quanto internamente. Seu ato não teria sido apenas justificado, mas também considerado heróico. Um heroísmo que vem sendo sistematicamente esquecido e deturpado pela memória que vinha sendo construída pelos militantes: "[...] enquanto isto, aqueles que lutaram e deram o sangue contra a subversão, são esquecidos" ${ }^{47}$.

Fator importante a ser considerado ainda é o argumento de que lhes caberia a preservação da integridade das Forças Armadas enquanto tais, face a infiltração de elementos subversivos em seu meio, sobretudo entre oficiais de média patente, em um processo político marcado por sua fragilidade e graus de corrupção.

Ainda justificaria não só o golpe, mas a intensidade da repressão, a percepção de que a mobilização das forças de esquerda era um elemento de guerra (fria e suja). Em um estado de guerra, sempre são produzidos efeitos colaterais que, por mais que sejam minimizados, existem. Só que esse argumento de seguir uma lógica doutrinária é válido enquanto elemento legitimador apenas para os militares. O debate leninista de incorporação da luta armada como meio de expropriação dos meios de poder da burguesia enquanto classe dominante não pode ser entendido enquanto uma estratégia inerente a este mesmo processo de guerra. Guerrilheiros precisam ser desqualificados de suas ideologias e apresentados como "delinquentes", por não partilharem valores específicos da instituição militar. São traidores, conforme argumenta N2, ao narrar a história de Lamarca - um desertor, terrorista, assaltante de banco e incentivador de guerrilhas, que deve entrar para a história como um terrorista, e não como um herói -, e de Nahuel Moreno, que, ao ser interrogado por N2, teria entregado as organizações representantes da Quarta 
Nunca foram heróis! A disputa pela imposição de significados...

Internacional no Brasil, em troca da abertura de uma livraria "de livros do Trotski” (a viúva do Trotski teria dados a Nahuel os direitos autorais sobre suas obras), e da legalização da então Convergência Socialista, o PST. Outra: ao recorrerem ao uso da violência, o que seria justificável doutrinariamente em uma guerra, conforme argumentam os militares, os militantes no país são apenas sanguinários, a exemplo dos "Irmãos Metralha", conforme o autor designa a família composta por Daniel, Derly, Devanir, Jairo e Joel José de Carvalho, cujo membro mais radical, Devanir, no exercício de sua militância, "[...] pôde livremente desenvolver seus apetites pela violência", ou concretizar seus sonhos: "roubar e matar"

Aliás, não são poucas as incoerências que podem ser identificadas no discurso de $\mathrm{N} 2$, retiradas da entrevista realizada em julho de 2007 e que, provavelmente, refletem características desta linha de militares ultraconservadores de modo geral. A recusa em reavaliar sua atuação exemplifica casos em que participou de interrogatórios, como o de Nahuel, mas afirma que nunca fez ações: "[...] eu nunca torturei ninguém, eu nunca fiz ações, eu fui analista, trabalhava com a cabeça. Mas eles dizem que o analista também é torturador, e aí danou-se, não tem jeito"49. Afirma, categoricamente, que não quer falar sobre o projeto ORVIL, “[...] não, eu não quero falar não. Até porque eu tenho a minha família aqui. O problema é essa esquerda revanchista aí..." Mas não apenas publica sistematicamente sobre o tema no site TERNUMA, assim, como estabelece como meta de vida, se dedicar à elaboração de denuncias sobre as ações da esquerda: "E vou passar a escrever também. Esse vai ser o final da minha vida, escrever estas coisas aí."

É consciente de que narra uma história, muitas vezes deturpada pelo processo de criação dos documentos: “[...] nós nos baseávamos em informes, informações, em relatórios periódicos [...] e, principalmente, depoimentos dos interrogatórios", mas, conforme afirma, "[...] houve realmente casos em que aconteceu uma coisa e criou-se um documento diferente". Justifica-se, argumentando que fazia o correto, conferindo tudo, para apresentar apenas os fatos. Destaca, inclusive, o fato de ter encontrado um "terrorista morto assaltando banco", e procura construir um discurso em que o equívoco na elaboração seria concernente apenas a aspectos factuais. 
Sem dúvidas, encontramo-nos mediante um falso modesto que, na luta pela imposição da sua narrativa, não mede esforços para alcançar reconhecimento junto a seus pares, pois apenas os militares saberão, a partir da divulgação de seu pseudônimo (realizada com nossa contribuição, é verdade), de quem se trata. Em entrevista realizada em 2006, trata da publicação do livro Verdade Sufocada, por Brilhante Ustra, mas destaca o fato de que "[...] ele não fala meu nome, é claro". Apenas uma obviedade em relação à necessidade de sigilo da identidade, ou um "é claro", em função de que Ustra narra o projeto, mas que naquele espaço não era possível evidenciar seus esforços? No decorrer da exposição que o projeto alcança em 2007, não apenas aceita conceder a entrevista sobre o assunto (apenas havíamos tomado conhecimento de que ele participara do projeto, porque, em entrevista anterior, sobre tema distinto, havia tocado no tema), como procuram destacar todas as evidências de sua iniciativa e empenho na execução do projeto, em detrimento de uma perspectiva de equipe, evidenciado nos outros espaços que falam do ORVIL: "O que eu quero dizer é que a ideia dentro do CIE já existia, de escrever o livro, e tá aqui a prova"; "Eu trabalhava sozinho"; "Fui eu quem escrevi a biografia do Lamarca. Eu escrevi, está no TERNUMA". Poucos seriam os que possuíam reconhecida competência para desenvolver o trabalho como fazia, como era o caso raro de quem o sucedeu na execução do projeto: "Eu, o número 3 [...] O resto é o resto, que conviviam e comeram na nossa mão". Uma necessidade de reconhecimento claramente expressa nesta declaração:

Por exemplo, isso aqui... Você conhece isso aqui? Isso aqui é um grupo de Minas Gerais. Inconfidência lá de Minas Gerais. Isso aqui eu recebi agora. Fala sobre o Livro Negro... Isso aqui eu não conheço: o Livro Negro... Aí eu olhei isso daqui... Está vendo esse desenho aqui? Isso aqui fui eu quem fiz esse desenho aí. Fazia parte das minhas palestras.

Ou nesta, na qual, inclusive, evidencia disputas institucionais existentes no âmbito da comunidade de informações: "Aí eu escrevi 
Nunca foram heróis! A disputa pela imposição de significados...

tudo e mandei pro SNI, que não entendia nada disso. Aquela gente nunca soube p... nenhuma. Essa é a realidade".

Tratamos de alguém que procura fazer dos embates presentes, claramente, um espaço de disputa política. Um "historiador" demasiadamente subjetivo, que opta pelo esquecimento da atuação de um grupo de direita radical terrorista no Brasil, que atuava desde a década de 1940, muito antes da "revolução democrática" "50, e que manuseia fontes de questionável veracidade, como se contivessem "verdades históricas". O que aconteceria a nós, efetivamente historiadores, se tomássemos estes arquivos como verdadeiros e não os confrontássemos com os testemunhos daqueles que foram perseguidos pelo regime? Que história estaríamos forjando?

A esquerda também recorreu ao uso da violência, assim como existem algumas posturas que podem ser consideradas oportunistas no processo de revisão do passado e na aplicação da política de indenizações. Mas se os militares veem sua aplicação da violência como uma necessidade, como uma resposta à atuação dos guerrilheiros, militantes de esquerda e membros da oposição (porque muitos foram os torturados que não pegaram em armas), cabe ressaltar que, para a esquerda, a aplicação da violência visava a destituir a burguesia de seus meios de poder. Esse era o caminho preconizado no processo de transformação social, que conduziria, sobretudo, a uma redução, das desigualdades. A aplicação da violência foi efetiva, mas seria legitima na concepção da esquerda daquele momento, da mesma forma em que uma garotinha, na iminência de ser estuprada, impõe resistência a seu agressor, por meio de socos e pontapés. Nesta guerra, os militares privilegiaram a individualização do adversário e sua localização, acima da sua dignidade. Mesmo em termos doutrinários, é impossível falar que houve proporcionalidade no desencadeamento da repressão. No máximo, o uso da força foi proporcional à projeção que alguns militares, amparados em seus valores institucionais, realizaram sobre seus inimigos. Ou seja, também nunca foram heróis! Nem militantes de esquerda, nem militares. 


\section{NEVER WERE HEROES! THE DISPUTE OVER THE IMPOSI- TION OF MEANINGS AROUND THE USE OF VIOLENCE IN THE BRAZILIAN DICTATORSHIP, THROUGH A READING OF ORVIL PROJECT}

Abstract: This paper covers the process of creation, implementation, and dissemination of Project ORVIL, from the perspective of one of its main performers; the then Lieutenant Colonel "N2". The project was thought in early 1984, and proposed the establishment of a "History Writing" that shifted from the perspective that was being used by left-wing militants about torture in Brazil, mainly from the Amnesty, and disseminated through interviews and an extensive memorial bibliography. Permeated by the speeches concerning to memory and disputes held around their imposition, this paper looks from the individual perspective and how this construction was transplanted to an institutional setting. We seek to a) understand how a given military group, markedly ultra-conservatives, saw the scenario of the military coup and the implementation of repression; $b$ ) realize what strategies were and still are used to tell and reminds us that past, and finally; c) identify which factors have the capability to intervene in this construction, both from a endogenous perspective, in terms of institution, as in a exogenous perspective.

Keywords: ORVIL. Information Services. Torture. Memory. Brazilian Dictatorship. Secret Services.

\section{Notas}

${ }^{1}$ Terrorismo Nunca Mais, criado em resposta ao projeto Brasil Nunca Mais. Disponível em: <www.ternuma.com.br>.

${ }^{2}$ O Jornal Inconfidência foi fundado em 1994, e é um periódico mensal, de distribuição em âmbito nacional. Seu conteúdo está identificado "na luta contra o comunismo e a corrupção, pelo fortalecimento das forças armadas e pela defesa da vida humana, da família tradicional e dos valores conservadores da sociedade". Disponível em: <www.grupoinconfidencia.com.br>.

${ }^{3}$ Entrevistas concedidas à autora, Priscila Brandão, sob condição de reserva, realizadas em Cuiabá (11 de agosto de 2006), e no Rio de Janeiro (05 de julho de 2007). ${ }^{4}$ Uma Apreciação é o Conbecimento resultante de raciocínio elaborado por um profissional de inteligência, que expressa o seu estado de opinião frente à verdade, sobre fato ou situação passados e/ou presentes, admitindo a realização de projeções.

${ }^{5}$ Em termos doutrinários, Informe é o conbecimento resultante de juízo formulado por um profissional de inteligência, que expressa seu estado de certeza, opinião ou de dúvida frente à verdade sobre fato ou situação passado e/ou presente. 
${ }^{6}$ Entrevista com N2, concedida sob condição de reserva, em 05 de julho de 2007.

${ }^{7}$ Os primeiros clássicos memorialísticos de militantes de esquerda começaram a sair ainda em fins dos anos de 1970. O primeiro, Em câmara lenta, de Renato Tapajós, data de 1977 e causou a reação de setores conservadores, que acusaram o livro de ser um "instrumento de guerra revolucionária”, ao ponto de levar o autor a ficar 10 dias preso, incomunicável, mesmo não havendo algum empecilho legal à sua circulação. Passados 15 dias da prisão de Tapajós, o livro foi censurado. Os demais livros saíram a partir de 1979. MAUÉS. Eloísa. Em câmara lenta: historia do livro, experiência histórica da repressão e narrativa literária. Dissertação. USP, 2008; TAPAJÓS, Renato. Em câmara lenta. São Paulo: Alfa-Ômega, 1977; GABEIRA, Fernando. O que é isso companheiro? Rio de Janeiro: CODECRI, 1979. SIRKIS, Alfredo. Os carbonários. Global: São Paulo, 1981; DANIEL. Herbert. Passagem para o próximo sonho. Rio de Janeiro: CODECRI, 1982.

${ }^{8}$ Apreciação S/Nº - A1. 27/03/1984. p. 01

${ }^{9}$ Apreciação S/Nº - A1. 27/03/1984. p. 01

${ }^{10}$ Idem. p. 01

${ }^{11}$ Idem. p. 02

${ }^{12}$ Idem. p. 02

13 Idem. p. 03.

${ }^{14}$ Sobre o tema, ver: ANTUNES, Priscila C. Brandão. SNI e ABIN: uma leitura dos serviços secretos brasileiros ao longo do século XX. Rio de Janeiro: Ed. FGV, 2002.

${ }^{15}$ Entrevista realizada em Cuiabá, em 11 de julho de 2006.

${ }^{16}$ Entrevista de N2 citada.

${ }^{17}$ Entrevista de N2 citada.

${ }^{18}$ Entrevista de N2 citada.

${ }^{19}$ Idem.

${ }^{20}$ Idem.

${ }^{21}$ Idem.

${ }^{22}$ Idem.

${ }^{23}$ As quatro tentativas de tomada de poder - ORVIL. p. XV-XVI. Retirado de: http://www.averdadesufocada.com/images/orvil/orvil_completo.pdf, conferido em 15 ago. 2011.

${ }^{24}$ Idem. p. XVI-XVII.

${ }^{25}$ Entrevista de N2 citada.

${ }^{26}$ As quatro tentativas de tomada de poder - ORVIL. p. 22. Retirado de: http:// www.averdadesufocada.com/images/orvil/orvil_completo.pdf, acesso em: 15 ago. 2011.

${ }^{27}$ Idem. p. 23

28 Disponível em: <http://www.ternuma.com.br/ternuma/index. php?open $=20 \& d a t a=26 \&$ tipo $=2>$. Acesso em: 30 jul. 2011. 


\section{Priscila Carlos Brandão, Isabel Cristina Leite}

29 Disponível em: <http://www.ternuma.com.br/ternuma/index. php?open $=20 \&$ data $=26 \&$ tipo $=2>$. Acesso em: 30 jul. 2011.

${ }^{30}$ Maiores informações sobre estas cisões ver: LEITE, Isabel. Comandos de Libertação Nacional. Oposição armada à ditadura militar em Minas Gerais. Dissertação. UFMG, 2009.

${ }^{31}$ As quatro tentativas de tomada de poder-ORVIL. p. 472. Retirado de: http:// www.averdadesufocada.com/images/orvil/orvil_completo.pdf, acesso em: 15 ago. 2011.

${ }^{32}$ Idem. p. 836.

${ }^{33}$ As quatro tentativas de tomada de poder-ORVIL. p. 837. Retirado de: http:/ / www.averdadesufocada.com/images/orvil/orvil_completo.pdf, acesso em: 15 ago. 2011.

${ }^{34}$ Idem. p. 839.

${ }^{35}$ Idem. p. 842.

${ }^{36}$ As quatro tentativas de tomada de poder-ORVIL. p. 856. Retirado de: http:// www.averdadesufocada.com/images/orvil/orvil_completo.pdf, acesso em: 15 ago. 2011.

${ }^{37} \mathrm{~N} 212$ de julho de 2007

${ }^{38}$ O Livro era uma arma, diz general. Estado de Minas. Reportagem Especial.12 de abril de 2007, p. 4.

${ }^{39}$ Dentre os livros que tiveram o ORVIL como base, estão: Rompendo o silêncio, $A$ grande mentira, Guerrilha do Araguaia: a grande verdade.

${ }^{40} \mathrm{O}$ livro negro do terrorismo no Brasil. Estado de Minas. Reportagem Especial. 08 de abril de 2007; O Livro era uma arma, diz general. Estado de Minas. Reportagem Especial.12 de abril de 2007.

${ }^{41}$ FIGUEIREDO, Lucas. Olho por olho. Os livros proibidos da ditadura. São Paulo: Record, 2009.

${ }^{42}$ Parte desta discussão está em: LEITE, Isabel. Os arquivos da repressão e a luta pela memória da ditadura militar. Revista Eletrônica de História do Brasil. n. 9. UFJF. 2007. Disponível em: http://www.ufff.br/rehb/files/2010/03/v9-n1-a11.pdf. acesso em: 15 ago. 2011.

${ }^{43}$ Disponível em: www.grupoinconfidencia.com.br/jornais/108/jornal108.pdf ${ }^{44}$ Idem.

${ }^{45}$ REIS FILHO, Daniel. Ditadura militar, esquerdas e sociedade. Rio de Janeiro: Zahar, 2005, p. 70.

46 "Nota do Centro de Comunicação do Exército". Folha de São Paulo, terça-feira, 19 de outubro de 2004.

${ }^{47}$ Apreciação S/No-A1, de 27/03/1984.

48 Disponível em: http://www.ternuma.com.br/ternuma/index. php?open $=20 \&$ data $=164 \&$ tipo=2. Acesso em: 30 jul. 2011. 
Nunca foram heróis! A disputa pela imposição de significados...

${ }^{49}$ Entrevista N2, citada.

${ }^{50}$ Ver: ARGOLO, José A.; RIBEIRO, Kátia; FORTUNATO, Luiz Alberto. A direita explosiva no Brasil. Rio de Janeiro: Editora Mauad, 1996. Bibliografia

\section{Referências}

ACHUGAR, Hugo. El lugar de la memoria, a propósito de monumentos. In: JELIN, Elizabeth; LANGLAND, Victoria (Comps.). Monumentos, memoriales y marcas territoriales. Madrid: Siglo Veintiuno de España Editores y Siglo Veintiuno de Argentina Editores, 2003.

AGUERO, Felipe; HERSHBERG, Eric (Comps.). Memorias militares sobre La repression em El Cono Sur: visiones em disputa em dictadura y deocracia Madrid: Siglo XXI, 2005.

ANTUNES, Priscila C. Brandão. SNI e ABIN: uma leitura dos serviços secretos brasileiros ao longo do século XX. Rio de Janeiro: Editora Fundação Getúlio Vargas, 2002.

ARGOLO, José A.; RIBEIRO, Kátia; FORTUNATO, Luiz Alberto. A direita explosiva no Brasil. Rio de Janeiro: Editora Mauad, 1996.

DANIEL, Herbert. Passagem para o próximo sonho. Rio de Janeiro: CODECRI, 1982.

D'ARAÚJO, Maria Celina; SOARES, Glaucio; CASTRO, Celso.Os anos de chumbo: a memória militar sobre a repressão. Rio de Janeiro:Relume-Dumará, 1994.

FIGUEIREDO, Lucas. Otho por olho. Os livros proibidos da ditadura. São Paulo: Record, 2009.

GABEIRA, Fernando. O que é isso, companheiro? Rio de Janeiro: CODECRI, 1979.

HUYSSEN, Andreas. Resistência à memória: os usos e abusos do esquecimento público. In: BRAGANÇA, Anibal; MOREIRA, Sônia. Comunicação, acontecimento e memória. São Paulo: INTERCOM, 2004.

JELIN, Elizabeth. Las luchas por la memoria: hacia un programa de investigación comparative. Trabajo preparado para su discusión en el seminario sobre el programa Memoria colectiva y represión: Perspectivas comparativas sobre el proceso de democratización en el Cono Sur de América Latina. Organizado por el SSRC, Montevideo, 16-17 de noviembre de 1998.

JELIN, Elizabeth; CATELA, Ludmila (Comps.). Los archivos de la repression: Documentos, memoria y verdad. Madrid: Siglo XXI, 2002 
JELIN, Elizabeth. Introdución. In: JELIN, Elizabeth. Comemoraciones: las disputas en las fechas in-felices. Madrid: Siglo XXI, 2002.

JELIN, Elizabeth; KAUFMAN, Susana. Los niveles de la memoria. Entrepasados. Año X. n. 20, 2001.

LEITE, Isabel. Comandos de Libertação Nacional. Oposição armada à ditadura militar em Minas Gerais. Dissertação. UFMG, 2009.

MOTTA, Rodrigo Pato. Em guarda contra o perigo vermelho. São Paulo: Perspectiva, 2002.

NORA, Pierre. Les lieux de Memoire. In: La Republique. Paris: Gallimard, 1984. REIS FILHO, Daniel; SÁ, Jair. Imagens da revolução Rio de Janeiro: Marco Zero, 1985.

REIS FILHO, Daniel. Ditadura militar, esquerdas e sociedade. Rio de Janeiro: Zahar, 2005.

SIRKIS, Alfredo. Os carbonários. Global: São Paulo, 1981.

TAPAJÓS, Renato. Em câmara lenta. São Paulo: Alfa-Ômega, 1977.

Recebido em: 16/05/2012

Aprovado em: 11/07/2012 